\title{
Comparison of Multi-Fractal Antenna with Star Shaped Fractal Antenna for Wireless Applications
}

\author{
Maninder Singh \\ M.Tech Scholar \\ Electronics and Communication Engineering Deptt. \\ Amritsar College of Engineering and Technology, \\ Amritsar
}

\begin{abstract}
This paper presents the comparison of two different fractal antennas. Both the antennas are designed by using FR4 glass epoxy substrate with relative permittivity of 4.4 and $1.6 \mathrm{~mm}$ thickness. The different parameters such as return loss, VSWR, gain and bandwidth of existing antenna (multi-fractal antenna) are compared with designed antenna (star shaped fractal antenna) which shows that the designed antenna have more better results as compared with the existing antenna. The designed antenna was simulated by using HFSS V13 software and the antenna can be used for different wireless applications such as WLAN, satellite communication, long distance radar telecommunication etc.
\end{abstract}

\section{Keywords}

HFSS, VSWR, Multi-fractal.

\section{INTRODUCTION}

In 1995 the concept of fractal antenna geometries was put forwarded by Nathen Cohen [1]. The self-similarity and space-filling properties of fractal antenna are used to design the antenna for multiband and wideband characteristics. Fractal antennas repeat their geometries by a particular scale in different iterations to get better results [3]. In wireless communication the multiband and wideband characteristics is desirable to design more effective antennas. These characteristics can be achieved by designing the fractal antenna or by making the defective ground plane structure [4]. The main advantages of the fractal antennas are that these antennas have circular and linear polarization, low profile, light weight, low fabrication cost and mechanically robust when mounted on stiff surfaces [5]. In this paper comparison of two different shapes of fractal antennas are discussed. The different parameters and designing procedure of existing antenna (multi-fractal antenna) [1] and the designed star shaped fractal antenna are discussed and compared in this work

\section{ANTENNA DESIGN}

The different iterations of existing multi-fractal antenna [1] and the designed star shaped fractal antenna are shown in Figure 1 and Figure 2 respectively. The FR4 epoxy substrate with dielectric constant 4.4 , thickness $1.6 \mathrm{~mm}$ and resonant frequency of $5 \mathrm{GHz}$ are used for the designing of multi-fractal antenna and star shaped fractal antenna. The side lengths of the triangular antennas are calculated by using equation 1 and are found to be $19.04 \mathrm{~mm}$.

$W_{t}(m m)=\frac{2 X c}{3 X f_{r} X \sqrt{\varepsilon_{r}}}$

\author{
Narinder Sharma \\ Associate Professor \\ Electronics and Communication Engineering Deptt. \\ Amritsar College of Engineering and Technology, \\ Amritsar
}

$f_{r}=$ resonant frequency.

$\varepsilon_{r}=$ dielectric constant of substrate.

$W_{t}=$ side length of triangular patch.

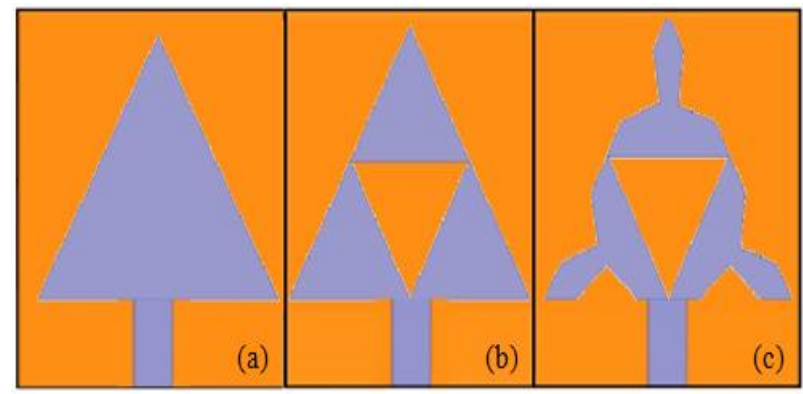

Figure 1: (a) $0^{\text {th }}$ iteration, (b) $1^{\text {st }}$ iteration and (c) $2^{\text {nd }}$ iteration of multi-fractal antenna [1]

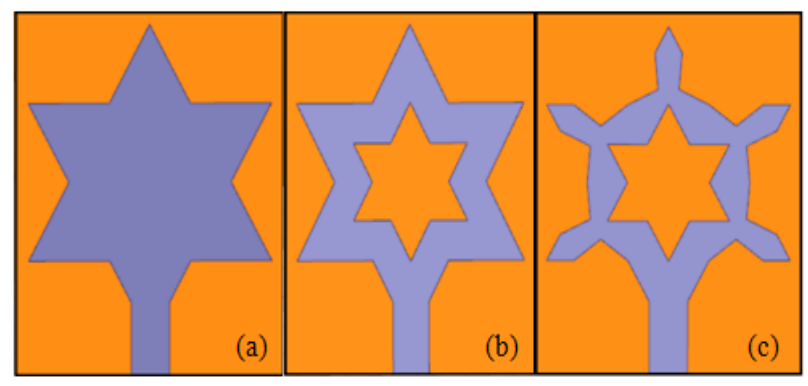

Figure 2: (a) $0^{\text {th }}$ iteration, (b) $1^{\text {st }}$ iteration and (c) $2^{\text {nd }}$ iteration of star shaped fractal antenna

The dimensions of the multi-fractal antenna [1] are as follows in which the length $(L f)$ and width $(W f)$ of feed line is $8 \mathrm{~mm}$ and $3 \mathrm{~mm}$ respectively. Dimension of partial ground plane $L g=5 \mathrm{~mm}$ and $W g=21.06 \mathrm{~mm}$. Dimension of the substrate Wsub, Lsub and Hsub are $25.5 \mathrm{~mm}, 21.06 \mathrm{~mm}$ and $1.6 \mathrm{~mm}$ respectively. Figure 3 shows the geometry of multi-fractal antenna in which the sierpinksi triangle cut out from the equilateral patch is having dimension, $\mathrm{Hst}=\mathrm{Ht} / 2=8.25 \mathrm{~mm}$ and side length of $9.53 \mathrm{~mm}$. The Koch curve cut out from the sides of the Sierpinski iterated structure are congruent to each other and have dimensions $\mathrm{Lk}=\mathrm{Ls} \times 2=4.76 \mathrm{~mm}, \mathrm{Hk}=$ $2 \mathrm{~mm}$ and $\mathrm{Ls}=\mathrm{Wt} / 8=2.38 \mathrm{~mm}$.

Where,

$\mathrm{C}=$ velocity of light in free space. 


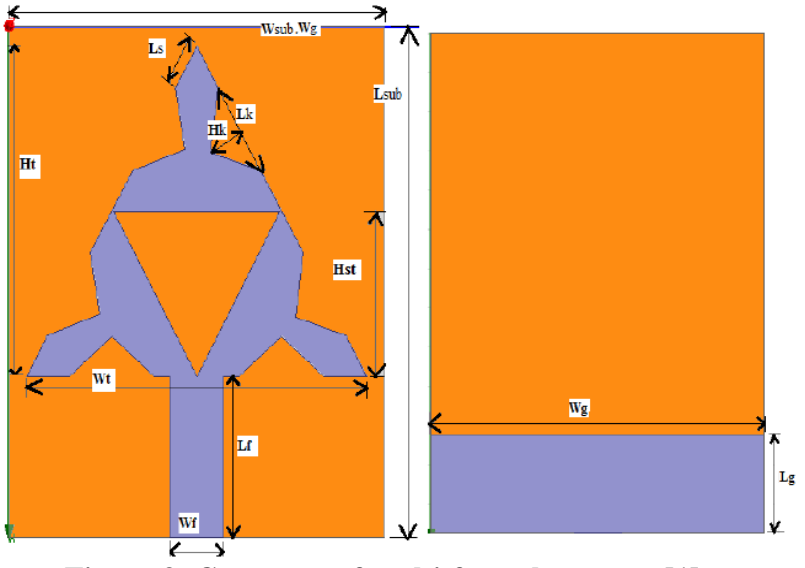

Figure 3: Geometry of multi-fractal antenna [1]

The length $L s$, width $W s$ and height of the substrate of star shaped fractal antenna is $25.5 \mathrm{~mm}, 21.06 \mathrm{~mm}$ and $1.6 \mathrm{~mm}$ respectively. Dimension of defected ground plane length $L g$ and width $W g$ are $4.8 \mathrm{~mm}$ and $21.06 \mathrm{~mm}$ respectively. The length $(L f)$ and width $(W f)$ of feed line is $5.09 \mathrm{~mm}$ and $3 \mathrm{~mm}$ respectively. The star shaped sierpinski iterated structure having the dimensions $\mathrm{Y}_{\mathrm{t}}=\mathrm{Y}_{\mathrm{k}} / 2=11 \mathrm{~mm}$ is cut out from the star shaped patch with a side length $C_{1}=3.17 \mathrm{~mm}$. The Koch curves cut out from each side of the star shaped patch having dimension $\mathrm{X}_{\mathrm{k}}=\mathrm{X}_{\mathrm{t} /} 2=1.58 \mathrm{~mm}, \mathrm{X}_{\mathrm{p}}=1.5 \mathrm{~mm}$ and $\mathrm{W}_{\mathrm{k}}=2.58$ $\mathrm{mm}$. The geometry of star shaped fractal antenna is shown in Figure 4.

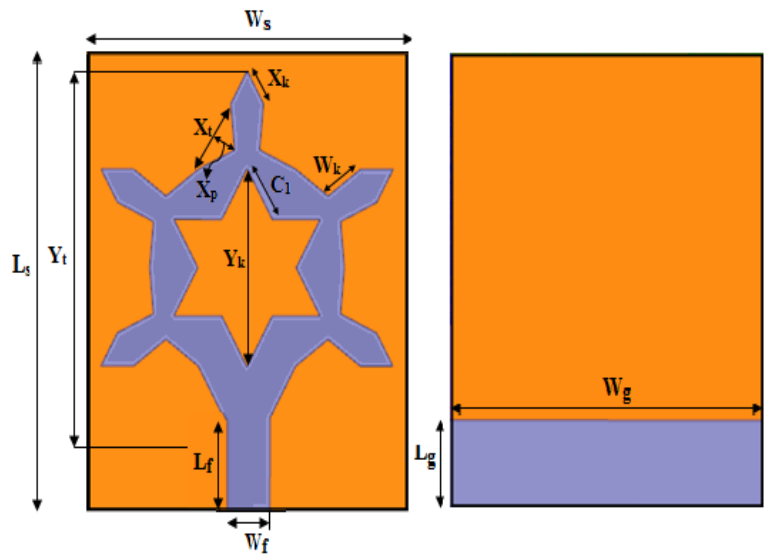

Figure 4: Geometry of star shaped fractal antenna

\section{RESULT AND DISCUSSIONS 3.1 Return loss and VSWR}

Return loss and VSWR are important parameters of antenna and the value of return loss is less than $-10 \mathrm{~dB}$ and the value of VSWR is less than 2 for the antenna to work effectively. The return loss curves of $0^{\text {th }}, 1^{\text {st }}$ and $2^{\text {nd }}$ iteration of multi-fractal antenna [1] and star shaped fractal antenna are shown in Figure 5 and Figure 6 respectively. The VSWR of multifractal antenna is not calculated but in this work the VSWR of existing antenna is also calculated and for the designed star shaped fractal antenna the VSWR curve is shown in Figure 7 and the comparisons of their values are shown in Table 1.

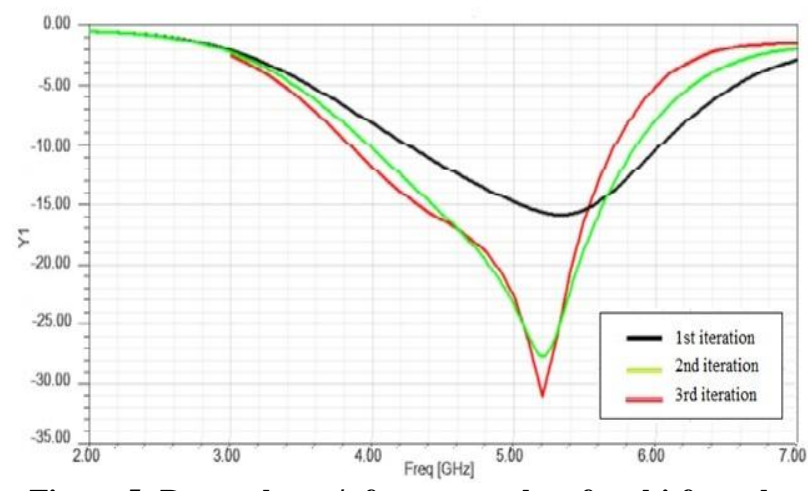

Figure 5: Return loss v/s frequency plot of multi-fractal antenna [1]

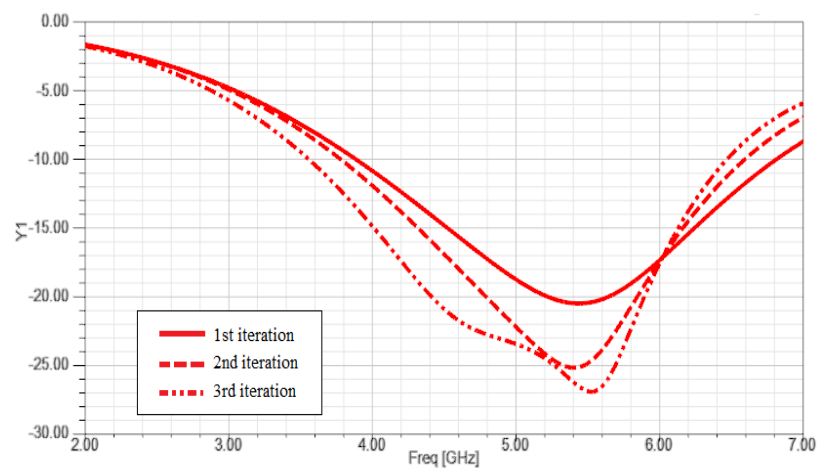

Figure 6: Return loss v/s frequency plot of star shaped fractal antenna

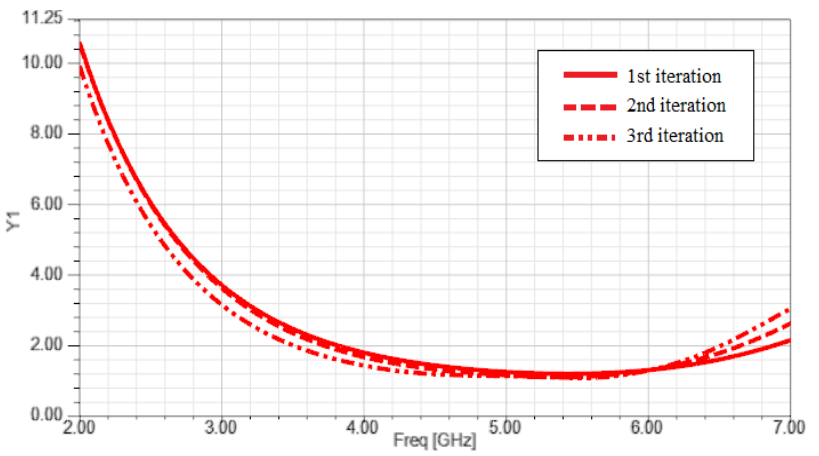

Figure 7: VSWR v/s frequency plot of star shaped fractal antenna

\subsection{Gain And Bandwidth}

The gain shows the directional capabilities and the efficiency of antenna. The desired value of the gain in greater than $3 \mathrm{~dB}$ for the antenna to work efficiently. The bandwidth can be calculated by subtracting the lower frequency from the upper frequency and the bandwidth percentage can be calculated by using the formula given below. The gain and bandwidth of the multi-fractal is studied and the gain and bandwidth of the star shaped fractal antenna is calculated and there comparison is shown in Table 1.

$$
\text { Bandwidth } \%=\frac{F_{2}-F_{1}}{F_{C}} \times 100
$$

Where,

$$
\begin{aligned}
& \text { F2 }=\text { Upper Frequency } \\
& F 1=\text { Lower Frequency } \\
& \text { Fc }=\text { Centre Frequency }
\end{aligned}
$$


Table 1. Comparison of different parameters of multifractal [1] with star shaped fractal antenna

\begin{tabular}{|c|c|c|c|}
\hline $\begin{array}{c}\text { Iteration } \\
\text { No. }\end{array}$ & Parameters & $\begin{array}{c}\text { Multi-Fractal } \\
\text { Antenna [1] }\end{array}$ & $\begin{array}{c}\text { Star Shaped } \\
\text { Fractal } \\
\text { Antenna }\end{array}$ \\
\hline \multirow{4}{*}{$0^{\text {th }}$} & Return loss & $-15.9 \mathrm{~dB}$ & $-20.47 \mathrm{~dB}$ \\
\cline { 2 - 4 } iteration & VSWR & 1.38 & 1.20 \\
\cline { 2 - 4 } & Gain & $2.95 \mathrm{~dB}$ & $5.45 \mathrm{~dB}$ \\
\cline { 2 - 4 } & $\begin{array}{c}\text { Bandwidth } \\
\%\end{array}$ & 33.9 & 53.49 \\
\hline \multirow{4}{*}{$1^{\text {st }}$} & Return loss & $-27.7 \mathrm{~dB}$ & $-25.14 \mathrm{~dB}$ \\
\cline { 2 - 4 } iteration & VSWR & 1.08 & 1.11 \\
\cline { 2 - 4 } & Gain & $3.21 \mathrm{~dB}$ & $6.76 \mathrm{~dB}$ \\
\cline { 2 - 4 } & $\begin{array}{c}\text { Bandwidth } \\
\%\end{array}$ & 36.22 & 52.04 \\
\hline \multirow{4}{*}{$2^{\text {nd }}$} & Return loss & $-31.3 \mathrm{~dB}$ & $-26.91 \mathrm{~dB}$ \\
\cline { 2 - 4 } iteration & VSWR & 1.05 & 1.09 \\
\cline { 2 - 4 } & Gain & $3.43 \mathrm{~dB}$ & $8.09 \mathrm{~dB}$ \\
\cline { 2 - 4 } & Bandwidth \\
$\%$ & 35.77 & 52.44 \\
\hline
\end{tabular}

\section{CONCLUSIONS}

The aim of this paper is to compare the existing multi-fractal antenna [1] design with the star shaped fractal antenna. The different parameters such as return loss, VSWR, Gain and bandwidth percentage of the designed antenna is compared with the existing fractal antenna which shows that the designed antenna shows the better results as compared to the existing antenna. The gain and bandwidth of the designed antenna increased on increasing the iteration number. Due to the better results of the designed antenna is more effective as compared to the existing antenna. Both the antennas can be used for different wireless applications but the designed antenna can be used more effectively for the practical applications.

\section{REFERENCES}

[1] B. K. Jeemon, K. Shambhavi and Z. C. Alex, "Design and analysis of multi-fractal antenna for UWB applications," IEEE International Conference on Emerging Trends in Computing

[2] B. H. Lincy, A. Srinivasan and B. Rajalakshmi, "Wideband Fractal Microstrip antenna for wireless applications," Proceedings of 2013 IEEE Conference on Information and Communications Technologies (ICT 2013).

[3] H. Orazi and H. Soleimani, "Miniaturization of the triangular patch antenna by the novel dual reverse arrow fractal," Institute of Engineering and Technology Journals, IET Microwave, Antenna and Propagation, pp. $1-7,2014$.

[4] A. S. Wadekar and S. V. Khobragade, "Design of multiband monopole triangular fractal antenna for GSM, Bluetooth and Wi-Fi," IEEE International Advanced Computing Conference (IACC), 2015.

[5] J. S. Sivia and S. S. Bhatia, "Design of fractal based microstrip rectangular patch antenna for multiband applications," IEEE International Advanced Computing Conference (IACC), 2015. 